\title{
SPARC promotes pancreatic cancer cell proliferation and migration through autocrine secretion into the extracellular milieu
}

\author{
KEHUA PAN $^{1 *}$, XINCE HUANG ${ }^{2 *}$ and XIUFEN JIA ${ }^{1}$ \\ Departments of ${ }^{1}$ Radiology and ${ }^{2}$ Hepatobiliary Surgery, The First Affiliated Hospital of \\ Wenzhou Medical University, Wenzhou, Zhejiang 325000, P.R. China
}

Received August 2, 2020; Accepted March 24, 2021

DOI: $10.3892 / \mathrm{ol} .2021 .12746$

\begin{abstract}
SPARC is a secreted glycoprotein that plays a complex and multifaceted role in tumour formation and progression. However, whether SPARC is an oncogene or a tumour suppressor is still unclear. Moreover, SPARC demonstrates potential in clinical pancreatic adenocarcinoma (PAAD) treatment, although it has been identified as an oncogene in some studies and a tumor suppressor in others. In the present study, a pan-cancer analysis of SPARC was carried out using The Cancer genome Atlas data, which demonstrated that SPARC was an oncogene in most cancer types and a cancer suppressor in others. In addition, SPARC expression was significantly upregulated in PAAD and associated with poor prognosis. SPARC also promoted the proliferation and migration of PANC-1 and SW1990 cell lines in vitro. SPARC was detected in the culture supernatant of PAAD cells and pancreatic acinar AR42J cells. SPARC regulated PAAD cell proliferation only when secreted into the extracellular milieu, thus explaining why the prognosis of patients with PAAD is correlated with the SPARC expression of both tumour cells and stromal cells. Collectively, the present findings demonstrated that the function of SPARC was associated with tumour type and that SPARC may represent an important oncogene in PAAD that merits further study.
\end{abstract}

Correspondence to: Dr Xiufen Jia, Department of Radiology, The First Affiliated Hospital of Wenzhou Medical University, Nanbaixiang, Ouhai, Wenzhou, Zhejiang 325000, P.R. China

E-mail: jiaxiufen@126.com

*Contributed equally

Abbreviations: SPARC, secreted protein acidic and rich in cysteine; PAAD, pancreatic adenocarcinoma; TCGA, The Cancer Genome Atlas; DLBL, diffuse large B-cell lymphoma; BRAD, breast invasive carcinoma; COAD, colon adenocarcinoma; CCK-8, Cell Counting Kit-8; MC3, Multi-Center Mutation-Calling in Multiple Cancers; MMP, matrix metalloproteinase; EMT, epithelial-to-mesenchymal transition; IHC, immunohistochemistry

Key words: SPARC, pan-cancer, pancreatic cancer, proliferation, migration, extracellular milieu

\section{Introduction}

Secreted protein acidic and rich in cysteine (SPARC) is a protein encoded by a single gene in human chromosome 5q31.1 (1). Mature SPARC has 286 amino acids with three distinct functional domains, including an $\mathrm{N}$-terminal acidic domain, a follistatin-like domain and a C-terminal domain (2). There are two calcium binding sites on this protein, which are the $\mathrm{N}$-terminus acidic domain that binds 5 to $8 \mathrm{Ca}^{2+}$ with a low affinity and a EF-hand motifs located in the C-terminus domain that bind a $\mathrm{Ca}^{2+}$ ion with a high affinity (1). As a secreted glycoprotein, SPARC binds several types of extracellular components, such as collagen, fibrin and minerals, and plays essential roles in physiological and pathological conditions, such as cataract formation, wound and defective organ healing, as well as tumorigenesis (1-3).

SPARC plays a complex and multifaceted role in tumours, including tumorigenesis, cellular malignant proliferation, drug resistance and metastasis $(4,5)$. The function of SPARC is associated with tumour type, cellular origin and the unique cancer milieu at both primary and metastatic sites. Different or even contradictory functions have been reported for SPARC in different tumour types (4-7). Moreover, the expression of SPARC has been reported to be associated with the prognosis of multiple tumours. Indeed, high expression of SPARC indicates good prognosis in diffuse large B-cell lymphoma (DLBL) (8) but poor prognosis in bladder urothelial carcinoma (BLAD), breast invasive carcinoma (BRAD) and colon adenocarcinoma (COAD) (9-11). Thus, SPARC appears to be oncogene in some tumours and a tumour suppressor in others.

Pancreatic adenocarcinoma (PAAD) is the most common pathological type of pancreatic cancer and one of the malignant diseases with the worst prognosis worldwide, with a median survival time of 6-10 months for locally advanced disease and 3-5 months for metastatic disease (12). SPARC has demonstrated prognostic and therapeutic potential, as it is expressed by peritumoral fibroblasts, but not PAAD cells, and is associated with poor prognosis for patients with PAAD (13). Another study demonstrated that increased SPARC expression in primary PAAD cells is also associated with poorer overall and disease-free survival (14). However, SPARC has also been reported to inhibit proliferation, promote apoptosis and enhance the chemosensitivity of pancreatic cancer cells to gemcitabine (15-17). In general, SPARC presents as an 
oncogene in clinical studies and is associated with poor prognosis in patients with PAAD $(13,14)$. However, in biological experimental studies, SPARC is generally presented as a tumour suppressor of PAAD (15-17).

Therefore, several questions remain to be addressed. First, a systematic pan-cancer analysis of SPARC is needed to determine whether it is an oncogene, a tumour suppressor, or both. Secondly, the function of SPARC in PAAD needs further clarification, and the contradicting results of clinical and biological research need to be unified. Finally, while stroma-derived SPARC is associated with poor prognosis in patients with PAAD, cancer cell-derived SPARC inhibits the proliferation and chemoresistance of PAAD cells $(13,15,17)$. Whether SPARC produced by tumour stromal cells vs. PAAD cells has the same effects on tumour growth and progression must be investigated. In the present study, a pan-cancer analysis of SPARC expression using The Cancer Genome Atlas (TCGA) data was carried out. This analysis confirmed that SPARC was an oncogene in some cancer types, but a tumour suppressor in others. Consistent with clinical data, this study also confirmed SPARC to be an oncogene in PAAD. This has important clinical implications for patients with PAAD. Moreover, SPARC was found to promote PAAD cell proliferation and migration only when secreted.

\section{Materials and methods}

Datasets. Mutation, RNA Sequencing (RNASeq) and clinical data of 10,182 patients were collected from TCGA (https://portal.gdc.cancer.gov/) with 33 cancer types: Adrenocortical carcinoma (ACC), bladder urothelial carcinoma (BLCA), BRCA, cervical squamous cell carcinoma (CESC), cholangiocarcinoma (CHOL), COAD, DLBL, oesophageal carcinoma (ESCA), glioblastoma multiforme (GBM), head and neck squamous carcinoma (HNSC), kidney chromophobe $(\mathrm{KICH})$, kidney renal clear cell carcinoma (KIRC), kidney renal papillary cell carcinoma (KIRP), bone marrow acute myeloid leukaemia (LAML), brain low grade glioma (LGG), liver hepatocellular carcinoma (LIHC), lung adenocarcinoma (LUAD), lung squamous carcinoma (LUSC), pleura mesothelioma (MESO), ovarian serous cystadenocarcinoma (OV), PAAD, adrenal phechromocytoma and paraganglioma (PCPG), prostate adenocarcinoma (PRAD), rectum adenocarcinoma (READ), soft tissue sarcoma (SARC), skin cutaneous melanoma (SKCM), stomach adenocarcinoma (STAD), testicular germ cell tumours (TGCT), thyroid carcinoma (THCA), thymoma (THYM), uterine corpus endometrial carcinoma (UCEC), uterine carcinosarcoma (UCS) and uveal melanoma (UVM). For mutation data, the dataset produced by the Multi-Center Mutation Calling in Multiple Cancers (MC3) project was downloaded instead of the respective maf files of 33 types of cancer (18) (https://gdc.cancer. gov/about-data/publications/mc3-2017).

Patients and samples. All surgically removed PAAD and para-cancer specimens were obtained from the Department of Hepatobiliary Surgery of The First Affiliated Hospital, Wenzhou Medical University, between September 2016 and July 2019. Verbal informed consent was obtained from the patients. A total of 17 pairs of pathologically diagnosed PAAD and matched, para-cancer specimens were collected for RNA and protein extraction in accordance with institutional protocols. Para-cancer specimens were resected 0.3-0.5 cm from the tumour tissue. The patients age ranged between 52 and 77 years, with a mean age of 62.9 years and a median age of 64 years. The patients included 10 men and 7 women. The ethics of the study were reviewed and approved by the board of Wenzhou Medical University.

Cell culture and transfection. The PANC-1 and SW1990 human pancreatic cancer cell lines, the 293T human embryonic kidney cell line and the AR42J rat immortalized pancreatic acinar cell line were purchased from the Institute of Biochemistry and Cell Biology, The Chinese Academy of Science. PANC-1 and 293T cells were cultured in high-glucose DMEM medium (Gibco; Thermo Fisher Scientific, Inc.) with 10\% FBS (Sigma-Aldrich; Merck KGaA), $100 \mathrm{U} / \mathrm{ml}$ penicillin and $100 \mu \mathrm{g} / \mathrm{ml}$ streptomycin. SW1990 and AR42J were cultured in 1640 medium (Gibco; Thermo Fisher Scientific, Inc.) with the same supplements. Lipofectamine ${ }^{\circledR}$ 3000 (Invitrogen; Thermo Fisher Scientific, Inc.) and polyethyleneimine (Sigma-Aldrich; Merck KGaA) were used for the transfection of the PAAD cells and 293T cells, respectively, according to the manufacturers' protocols.

Plasmid construction. The pLenti-CMV-EGFP-3Flag vector was treated with $E c o$ RI and $B a m \mathrm{HI}$ at $37^{\circ} \mathrm{C}$ for linearization. Full-length SPARC cDNA (NCBI, accession no.NM_003118.4; https://www.ncbi.nlm.nih.gov/nuccore/NM_003118.4) was amplified from the cDNA of PANC-1 cells and cloned into the linearized vector using a seamless clone kit (cat. no. D7010S; Beyotime Institute of Biotechnology) according to the manufacturer's protocol.

For pLenti-CMV-SPARC ${ }^{\Delta \text { sig peptide }}$-Flag, the N-terminal 17 amino acids are the signal peptide of the SPARC protein and are essential for autocrine secretion (19). Using the full-length cDNA of SPARC as a template, we obtained cDNA with deleted codons for signal peptide via polymerase chain reaction (PCR) amplification while retaining the start codon. This SPARC ${ }^{\Delta \text { sig peptide }}$ cDNA was cloned into the linearized pLenti-CMV-EGFP-3Flag using the aforementioned seamless clone kit according to the manufacturer's protocol.

Silencing of SPARC by small interfering (si)RNA. SPARC was silenced using two siRNA molecules (Shanghai Biosun Sci\&Tech Co., Ltd.). The sequences of the SPARC siRNAs and the scrambled negative control siRNA are listed in Table I. The powder of SPARC and scrambled siRNAs was dissolved in RNase-free water to a concentration of $20 \mu \mathrm{M}$. Subsequently, $5 \mu \mathrm{l}$ of the siRNA solution was mixed with $150 \mu \mathrm{l}$ FBS-free medium at room temperature for $5 \mathrm{~min}$. At the same time, for each group of siRNA, $5 \mu 1$ Lipofectamine 3000 (Thermo Fisher Scientific, Inc.) was mixed with $150 \mu \mathrm{l} \mathrm{FBS-free} \mathrm{medium} \mathrm{at}$ room temperature for $5 \mathrm{~min}$. The siRNA solution was mixed with the Lipofectamine 3000 solution at room temperature for $20 \mathrm{~min}$, and the transfection mixture was added to a $6-\mathrm{cm}$ dish containing PANC-1 and SW1990 cells at 30-40\% confluency and $1.7 \mathrm{ml} \mathrm{FBS}$-free medium. The final siRNA concentration was $50 \mathrm{pM}$. The medium for transfection was replaced by medium containing FBS and antibiotics $5 \mathrm{~h}$ later, and cells 
Table I. Primers and siRNA molecules.

A, Primers

\begin{tabular}{ll} 
Primer name & Sequence, 5'-3' \\
\hline SPARC-mRNA-F & CGAAGAGGAGGTGGTGGCGGAAA \\
SPARC-mRNA-R & GGTTGTTGTCCTCATCCCTCTCATAC \\
GAPDH-F & CTCTCTGCTCCTCCTGTTCGACAG \\
GAPDH-R & AGGGGTCTTACTCCTTGGAGGCCA
\end{tabular}

B, siRNA

siRNA name

Sequence, 5'-3'

SIRNA-SPARC-1 UUAUCUAAUGUAUUCCUCCUG

SiRNA-SPARC-2 UAGUUCUUCUCGAAGUCCCGG

Negative control UUCUCCGAACGUGUCACGUTT

F, forward; R, reverse; siRNA, small interfering RNA; SPARC, secreted protein acidic and rich in cysteine.

were lysed for RNA or protein extraction $48 \mathrm{~h}$ later. For Cell Counting Kit-8 (CCK-8) assay, cells were re-cultured in a 96-well plate $24 \mathrm{~h}$ after transfection.

Overexpression $(O E)$ of SPARC. pLenti-CMV-SPARC-Flag and pLenti-CMV-SPARC $\Delta$ sig peptide-Flag vector were constructed as aforementioned. A pLenti-CMV-EGFP-3Flag vector with deleted EGFP cDNA was used as control. For transfection of PAAD cells, $3 \mu \mathrm{g}$ of control or OE vector was mixed with $150 \mu \mathrm{l}$ FBS-free medium at room temperature for $5 \mathrm{~min}$. At the same time, for each group of vectors, $5 \mu \mathrm{l}$ Lipofectamine 3000 was mixed with $150 \mu 1$ FBS-free medium at room temperature for $5 \mathrm{~min}$. Subsequently, the medium containing vector was mixed with the medium containing Lipofectamine 3000 at room temperature for $20 \mathrm{~min}$, and the transfection mixture was added to a $6-\mathrm{cm}$ dish containing PANC-1 and SW1990 cells at 30-40\% confluency and $1.7 \mathrm{ml}$ FBS-free medium. The medium for transfection was replaced by medium containing FBS and antibiotics $5 \mathrm{~h}$ later, and cells were lysed for RNA or protein extraction $48 \mathrm{~h}$ later. For CCK-8 assay, cells were re-cultured in a 96-well plate $24 \mathrm{~h}$ after transfection.

Silencing of SPARC by short hairpin (sh)RNA. The sequence of siRNA1 was used for the construction of SPARC shRNA using a pLKO.1-puro plasmid (Sigma-Aldrich; Merck KGaA). The pLKO.1-puro plasmid without shRNA insert was used as a negative control. For lentivirus production, $4 \mu \mathrm{g}$ of the shRNA vector, $3 \mu \mathrm{g}$ of psPAX and $2 \mu \mathrm{g}$ of pMD2.G were mixed with $150 \mu \mathrm{l} \mathrm{FBS}$-free medium at room temperature for 5 min. A total of $30 \mu \mathrm{l}$ of polyethylenimine (Sigma-Aldrich; Merck KGaA) was mixed with $150 \mu 1$ FBS-free medium at room temperature for $5 \mathrm{~min}$. Subsequently, the medium containing vector was mixed with the medium containing polyethylenimine at room temperature for $20 \mathrm{~min}$. The transfection mixture was added to the $10-\mathrm{cm}$ dishes with 293T cells at 50-60\% confluency. 293T cells were incubated at $37^{\circ} \mathrm{C}$, and the transfection medium was replaced $6 \mathrm{~h}$ later. Virus-containing medium was collected $48 \mathrm{~h}$ after transfection and was centrifugated at $3,000 \times \mathrm{g}$ and $4^{\circ} \mathrm{C}$ for $5 \mathrm{~min}$ to remove cell debris. For lentivirus infection, PAAD cells were cultured in 6-cm dishes at 40-50\% confluency, and the virus-containing medium was supplemented with $5 \mu \mathrm{g} / \mathrm{ml}$ polybrene to infect PAAD cells at $37^{\circ} \mathrm{C}$ for $24 \mathrm{~h}$. After $48 \mathrm{~h}$ of infection, the infected cells were positively selected with $2.5 \mu \mathrm{g} / \mathrm{ml}$ puromycin to eliminate uninfected cells to generate stable cell lines.

$R N A$ isolation and reverse transcription quantitative-PCR $(R T-q P C R)$. The total RNA from either PAAD or para-cancer tissues was extracted using TRI Reagent (Sigma-Aldrich; Merck KGaA) and chloroform according to the manufacturer's protocol. The RevertAid First Strand cDNA Synthesis kit (Thermo Fisher Scientific, Inc.) was used for first-strand cDNA synthesis. Briefly, $1 \mu \mathrm{g}$ total RNA was mixed with oligo-dT primer and nuclease-free water to a total volume of $12 \mu \mathrm{l}$, and the mixture was denatured at $65^{\circ} \mathrm{C}$ for $5 \mathrm{~min}$. Subsequently, reaction buffer, RNase inhibitor, dNTP, and reverse transcriptase were added to a total final volume of $20 \mu \mathrm{l}$. The mixture was incubated at $25^{\circ} \mathrm{C}$ for $5 \mathrm{~min}$, cDNA was synthesized at $42^{\circ} \mathrm{C}$ for $60 \mathrm{~min}$, and finally reverse transcriptase was denatured at $70^{\circ} \mathrm{C}$ for $5 \mathrm{~min}$.

qPCR was performed using the Quantstudio ${ }^{\mathrm{TM}} \mathrm{DX}$ Real-Time PCR Instrument (Applied Biosystems; Thermo Fisher Scientific, Inc.) using the Fast SYBR Green Master Mix (Applied Biosystems; Thermo Fisher Scientific, Inc.). cDNA was mixed with SYBR Green and primers to a final volume of $20 \mu \mathrm{l}$. The mixture was incubated at $95^{\circ} \mathrm{C}$ for $10 \mathrm{~min}$ for pre-denaturation, followed by 40 cycles at $95^{\circ} \mathrm{C}$ for $15 \mathrm{sec}$ and $62^{\circ} \mathrm{C}$ for $30 \mathrm{sec}$. The relative mRNA expression levels were normalized to the expression level of GAPDH using the $2^{-\Delta \Delta \mathrm{Cq}}$ method (20). The primers used for $\mathrm{qPCR}$ are listed in Table I.

CCK-8 and clone formation assay. The proliferation of PAAD cells was determined using a CCK-8 assay. PANC-1 and SW1990 cells were seeded in a 96-well plate at a density of $2 \times 10^{3}$ cells/well in triplicate. After a 12-h incubation, the cells adhered to the bottom of the plate, and this time was defined as day 0. At days 0-3 and 4, $100 \mu 1$ FBS-free medium with $10 \%$ CCK-8 reagent (Shanghai Yeasen Biotechnology Co., Ltd.) were added to the wells. After incubation at $37^{\circ} \mathrm{C}$ for $2 \mathrm{~h}$, the absorbance was measured with a microplate reader (BioTek Instruments, Inc.; Agilent Technologies, Inc.). A well with $100 \mu \mathrm{l}$ FBS-free medium and $10 \%$ CCK- 8 reagent without cells was used to determine the background absorbance. Cell viability was determined by subtracting the background absorbance from the experimental wells.

For the clone formation assay, $5 \times 10^{2}$ cells/well of PANC-1 and SW1990 cells were seeded into 6-well plates and cultured at $37^{\circ} \mathrm{C}$ for 14 days. The medium was changed every three days to avoid bias due to different evaporation rates. The cells were then fixed with methanol for $15 \mathrm{~min}$ at room temperature and stained with crystal violet for $5 \mathrm{~min}$ at room temperature (Beyotime Institute of Biotechnology). 
Table II. Antibodies.

\begin{tabular}{|c|c|c|c|}
\hline Antibody name & Supplier & Cat. no. & Dilution \\
\hline SPARC & Abcam & ab207743 & $1: 2,000$ \\
\hline$\beta$-actin & Sigma-Aldrich, Merck KGaA & A1978 & $1: 5,000$ \\
\hline Flag & Sigma-Aldrich, Merck KGaA & SAB4200071 & $1: 5,000$ \\
\hline AKT & Cell Signaling Technology, Inc. & 4691 & $1: 1,000$ \\
\hline $\mathrm{p}-\mathrm{AKT}$ & Cell Signaling Technology, Inc. & 4060 & $1: 1,000$ \\
\hline$\beta$-catenin & Abcam & ab32572 & $1: 5,000$ \\
\hline EGFR & Abcam & $\mathrm{ab} 32077$ & $1: 1,000$ \\
\hline p-EGFR & Cell Signaling Technology, Inc. & 3777 & $1: 1,000$ \\
\hline ERK & Abcam & ab184699 & $1: 2,000$ \\
\hline p-ERK & Abcam & ab214036 & $1: 2,000$ \\
\hline Stat3 & Bioworld & AP0365 & $1: 1,000$ \\
\hline p-stat3 & Abcam & $\mathrm{ab} 76315$ & $1: 2,000$ \\
\hline $\mathrm{p}-\mathrm{NF} \kappa \mathrm{B}$ & Abcam & $\mathrm{ab} 76302$ & $1: 1,000$ \\
\hline PI3K & Abcam & ab32089 & $1: 1,000$ \\
\hline MMP2 & Abcam & Ab92536 & $1: 1,000$ \\
\hline MMP7 & Santa Cruz Biotechnology, Inc. & sc-515703 & $1: 100$ \\
\hline MMP9 & Santa Cruz Biotechnology, Inc. & sc-393859 & $1: 200$ \\
\hline E-Cadherin & Santa Cruz Biotechnology, Inc. & sc-21791 & $1: 200$ \\
\hline $\mathrm{N}$-Cadherin & Abcam & ab98952 & $1: 2,000$ \\
\hline Vimentin & Santa Cruz Biotechnology, Inc. & sc-6260 & $1: 200$ \\
\hline Goat anti rabbit secondary antibody, HRP-conjugated & Sigma-Aldrich, Merck KGaA & SAB3700885 & $1: 10,000$ \\
\hline Goat anti mouse secondary antibody, HRP-conjugated & Sigma-Aldrich, Merck KGaA & SAB3700885 & $1: 10,000$ \\
\hline
\end{tabular}

SPARC, secreted protein acidic and rich in cysteine; $\mathrm{p}$, phosphorylated.

Transwell assay. The migration of the PANC-1 and SW1990 cells was assessed using 24-well BioCoat cell culture inserts (BD Biosciences) with an $8-\mu \mathrm{m}$ porosity polyethylene terephthalate membrane. The lower compartment contained RPMI-1640 (for SW1990) or DMEM (for PANC-1) with 10\% FBS as a chemoattractant. A total of $2 \times 10^{4}$ cells in $0.2 \mathrm{ml}$ FBS-free medium were plated in the upper compartment and incubated at $37^{\circ} \mathrm{C}$ for $48 \mathrm{~h}$. After incubation, the cells were fixed with methanol for $15 \mathrm{~min}$ at room temperature and stained with crystal violet for $5 \mathrm{~min}$ at room temperature. The images of Transwell assay were acquired using the Leica DMIL-LED inverted light laboratory microscope (Leica Microsystems $\mathrm{GmbH}$; magnification, x400).

Western blot analysis. Cells were lysed using a radioimmunoprecipitation assay lysis buffer with $10 \%$ phosphatase inhibitor (Shanghai Yeasen Biotechnology Co., Ltd.) and 1\% phenylmethylsulfonyl fluoride (Sigma-Aldrich; Merck KGaA) for $30 \mathrm{~min}$ at $4^{\circ} \mathrm{C}$. Total protein lysate was then collected, and the concentration was determined with a BCA Protein Assay kit (Beyotime Institute of Biotechnology). After denaturation at $100^{\circ} \mathrm{C}$ for $5 \mathrm{~min}, 20 \mu \mathrm{g}$ of protein samples from each group were resolved by SDS-PAGE using 10\% gels, then electrophoretically transferred to a PVDF. The PVDF membrane was blocked with 5\% skimmed milk (Shanghai Yeasen Biotechnology Co., Ltd.) for $1.5 \mathrm{~h}$ at room temperature. The membrane was incubated overnight with primary antibodies at $4^{\circ} \mathrm{C}$ and for $1 \mathrm{~h}$ with HRP-conjugated secondary antibodies $(1: 10,000)$ at $37^{\circ} \mathrm{C}$ (Table II). Amersham ECL Prime (Cytiva) was used to detect bands. The densities of the specific protein bands were visualized and captured using ImageQuant ${ }^{\mathrm{TM}} 400$ (GE Healthcare Life Sciences) and analysed using Image Lab 3.0 software (Bio-Rad Laboratories).

Collection of cellular supernatant and preparation for western blot analysis. The $293 \mathrm{~T}$ cells $\left(5 \times 10^{6}\right)$ transfected with a SPARC siRNA or OE vector, were seeded in two $10-\mathrm{cm}$ dishes. A volume of $8 \mathrm{ml}$ medium containing $10 \%$ FBS was added to each dish. The supernatant was collected $24 \mathrm{~h}$ later, centrifuged at $12,000 \times \mathrm{g}$ and $4^{\circ} \mathrm{C}$ for $5 \mathrm{~min}$, then added to 96-well plates containing the PANC-1 and SW1990 cells.

Western blot analysis was used to determine the difference of SPARC concentration in the supernatant. The supernatant was collected and centrifuged at $12,000 \times \mathrm{g}$ and $4^{\circ} \mathrm{C}$ for $5 \mathrm{~min}$; then, $5 \mathrm{X}$ SDS-PAGE loading buffer was added. After denaturation at $100^{\circ} \mathrm{C}$ for $5 \mathrm{~min}$, the samples were used for the western blot assay. To determine the concentration of the SPARC-Flag and SPARC ${ }^{\Delta \text { sig peptide }}$-Flag fusion protein in the supernatant, the same number of PANC-1 or SW1990 cells $\left(2 \times 10^{6}\right)$, transfected with the same amount of the control, SPARC-Flag, or SPARC ${ }^{\Delta \text { sig peptide }}$-Flag expression vector $(2 \mu \mathrm{g})$, were seeded in $6 \mathrm{~cm}$-dishes. The supernatant was collected $24 \mathrm{~h}$ later for western blot analysis, which was carried out as aforementioned. 

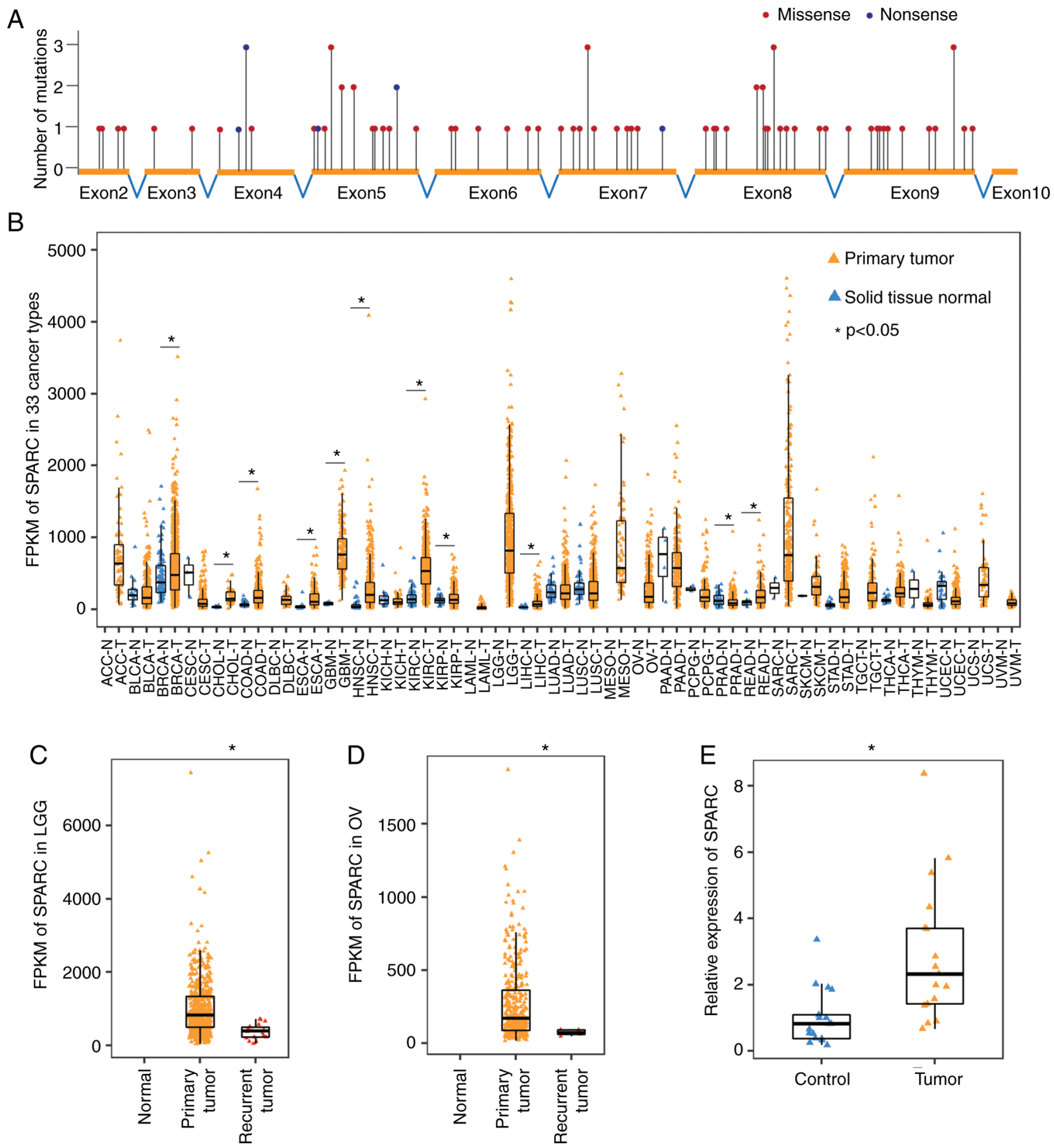

Figure 1. SPARC drives tumorigenesis through abnormal changes in expression but not gene mutations. (A) Single-nucleotide variations are uniformly distributed across the coding region of the SPARC gene (TCGA data). (B) Expression pattern of SPARC in 33 cancer types. SPARC expression is generally increased in various cancer types. Unpaired, two-tailed t-test (TCGA data). (C) Expression of SPARC decreased significantly in recurrent LGG, compared with the primary tumour. Unpaired, two-tailed t-test (TCGA data). (D) Expression of SPARC decreased significantly in recurrent OV, compared with the primary tumour. Unpaired, two-tailed t-test (TCGA data). (E) Reverse transcription-quantitative PCR demonstrated that SPARC expression increased significantly in PAAD, compared with the paired para-cancer tissue. $\mathrm{n}=17$, paired, two-tailed t-test. " $\mathrm{P}<0.05$. LGG, brain low-grade glioma; OV, ovarian serous cystadenocarcinoma; PAAD, pancreatic adenocarcinoma; TCGA, The Cancer Genome Atlas; FPKM, fragments per kilobase million; SPARC, secreted protein acidic and rich in cysteine.

Statistical analysis. The data are presented as the mean \pm SD. A paired or unpaired two-tailed t-test was used for comparisons between two groups. One-way ANOVA was used for comparisons of the multiple groups, and Tukey's method was used for the multiple comparison test. The Kaplan-Meier/log-rank method was used for the comparison of survival time between two groups if the survival curves did not cross. Otherwise, a Cramér-von Mises test was used instead. For survival analysis of each type of cancer, patients were split into two cohorts (high and low expression groups) where the P-value was 
A

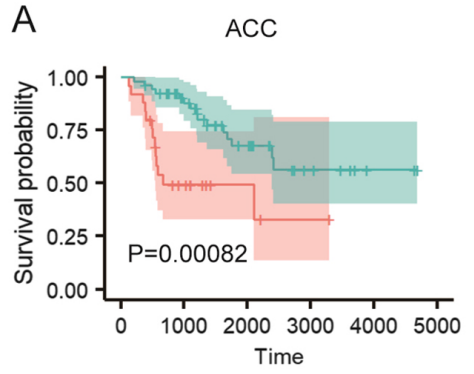

D

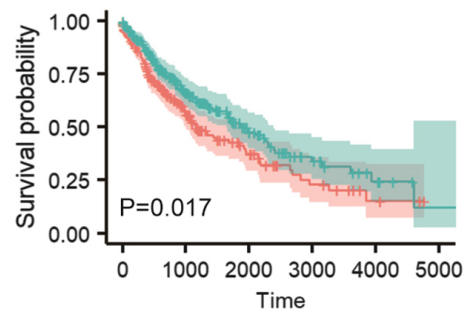

G

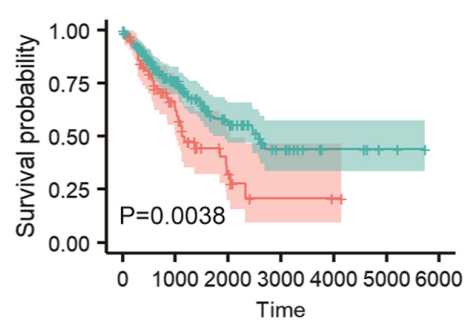

$J$

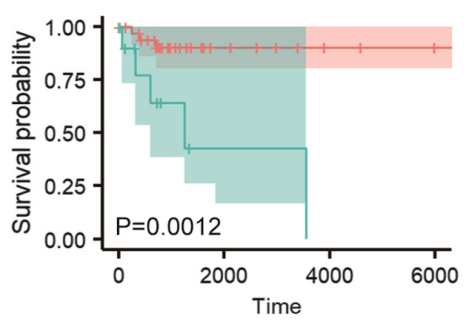

M

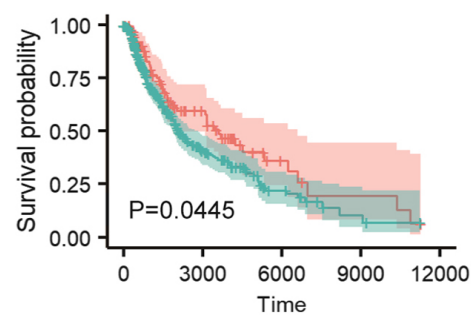

B

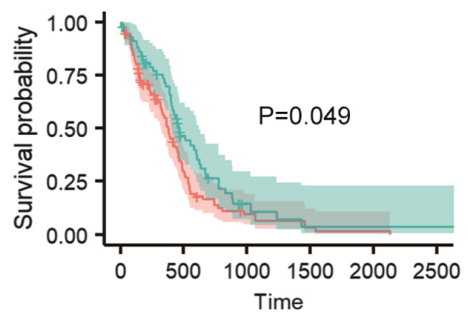

$\mathrm{E}$

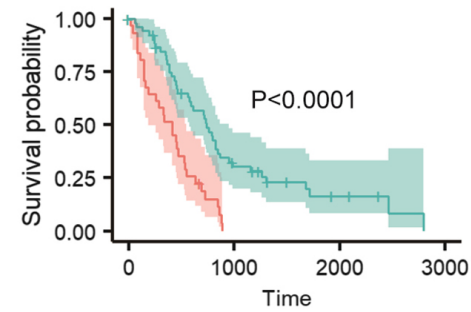

$\mathrm{H}$

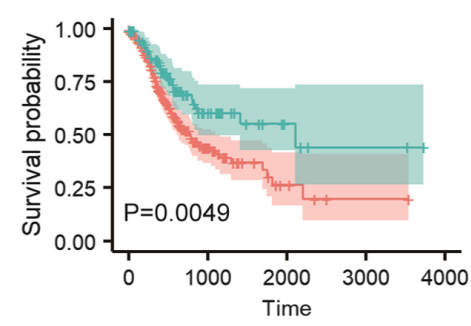

K

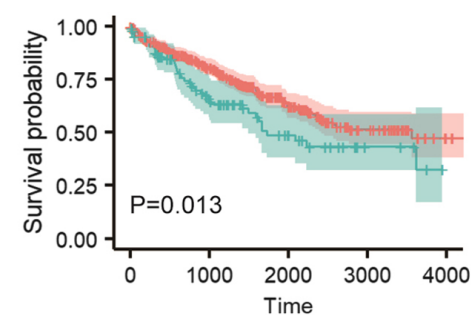

C $\quad$ KIRP

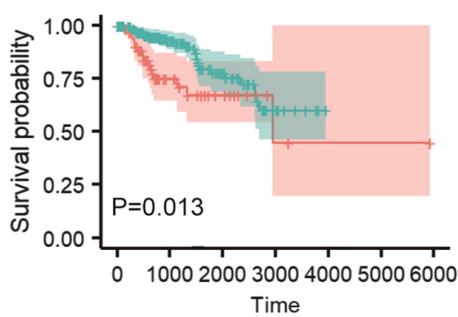

$\mathrm{F}$

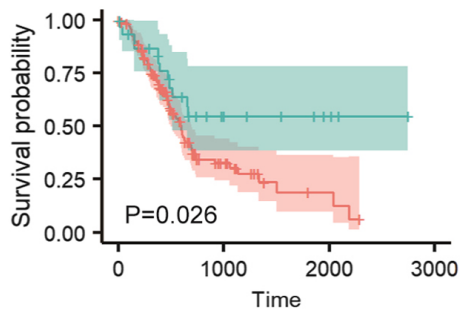

।

UVM

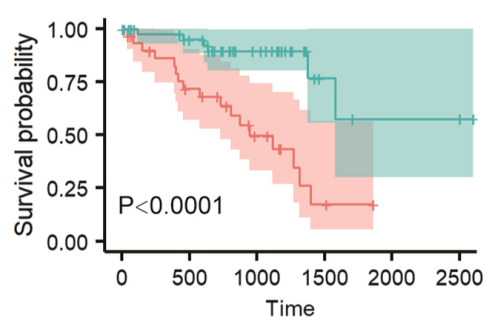

$\mathrm{L}$

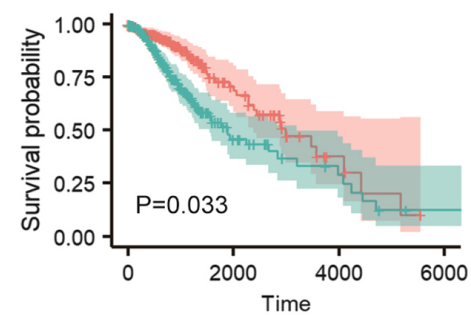

Strata

High SPARC expression

Low SPARC expression

Figure 2. SPARC is associated with prognosis of various cancers. (A-I) High SPARC expression is associated with worse prognosis in ACC, GBM, KIRP, LUSC, MESO, PAAD, SARC, STAD and UVM (TGCA data). (J-M) High SPARC expression is associated with improved prognosis in DLBL, KIRC, LGG and SKCM. (TCGA data). The Kaplan-Meier method with log-rank tests (ACC, GBM, LUSC, MESO, PAAD, SARC, STAD, UVM, DLBL, KIRC) or Cramér-von Mises tests (KIRP, LGG, SKCM) were used for comparison of survival time between two groups. SPARC, secreted protein acidic and rich in cysteine; ACC, adrenocortical carcinoma; GBM, glioblastoma multiforme; KIRP, kidney renal papillary cell carcinoma; LUSC, lung squamous carcinoma; MESO, pleura mesothelioma; SARC, soft tissue sarcoma; STAD, stomach adenocarcinoma; UVM, uveal melanoma; DLBL, diffuse large B-cell lymphoma; KIRC, kidney renal clear cell carcinoma; LGG, brain low-grade glioma; SKCM, skin cutaneous melanoma.

minimal. The cut-off value was achieved using the $\mathrm{R}$ packages 'survival' and 'survminer', with a loop function. To avoid the bias caused by the difference in the number of people in the two groups, each group comprising $\geq 25 \%$ of the total 
A

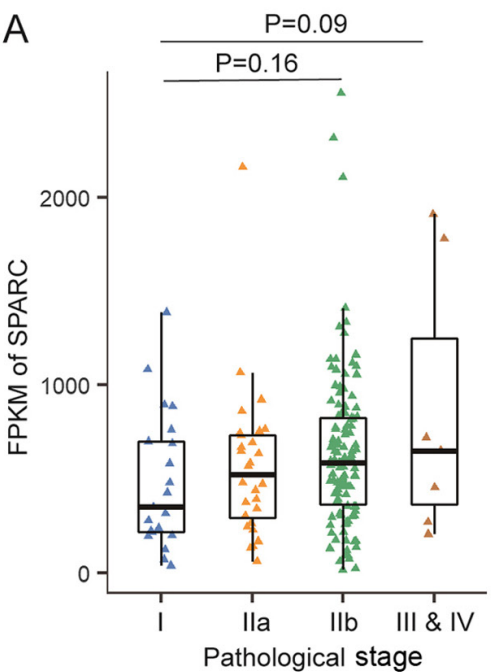

B

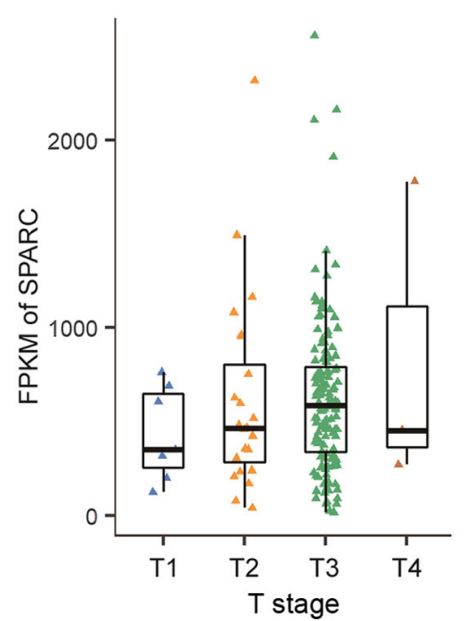

C

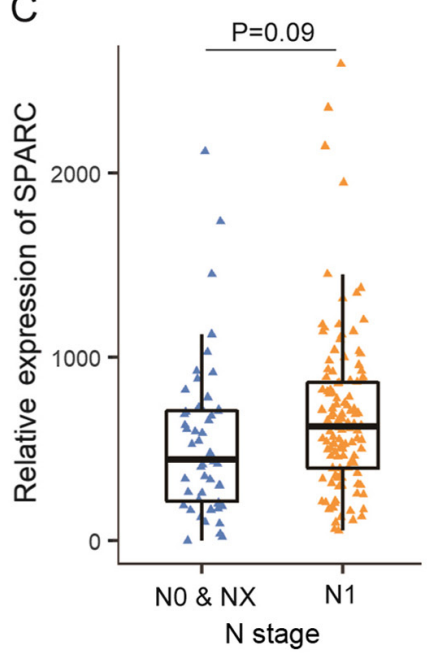

Figure 3. SPARC is not associated with the pathological stages of PAAD. (A) SPARC expression is not associated with PAAD pathological stage. One-way ANOVA with Tukey's post-hoc test (TCGA data). (B) SPARC expression is not associated with PAAD T stage. One-way ANOVA with Tukey's post-hoc Tukey's test (TCGA data). (C) SPARC expression is not associated with PAAD N stage. Unpaired, two-tailed t-test (TCGA data). PAAD, pancreatic adenocarcinoma; SPARC, secreted protein acidic and rich in cysteine; $\mathrm{T}$, tumour stage; $\mathrm{N}$, lymph node metastasis.

population. R-3.4 (https://www.r-project.org/) was used for the statistical analysis. $\mathrm{P}<0.05$ was considered to indicate a statistically significant difference.

\section{Results}

SPARC drives tumorigenesis through abnormal changes in expression but not gene mutations. First, the mutations in the SPARC gene from $>10,000$ cancer specimens across 33 cancer types were analysed. The mutation frequency of SPARC was very low, and only 101 single nucleotide variations were identified in the coding region of SPARC, including 21 synonymous, 71 missense, 8 nonsense and 1 splice site mutations. The 80 non-synonymous mutations were uniformly distributed across 64 coding base sites, with 1-3 mutations at each site, and no prominent recurrent mutations were found (Fig. 1A). It is likely that these mutations were only passengers and mutations of SPARC had no significant relationship with tumorigenesis. Interestingly, no insertion-deletion of the SPARC gene was found in the MC3 dataset, whether in-frame or frame-shift. The low mutation frequency and high conservation suggested that the normal function of SPARC was essential in tumour development. Thus, SPARC might be a potential negative selection gene during tumorigenesis (21).

Since mutations in the SPARC gene had no significant relationship to tumorigenesis, the expression of SPARC mRNA was then analysed in tumour and normal tissues. Among the 33 tumour types included in TCGA database, 24 tumour types contained the RNASeq data of both cancer and normal tissues. The expression of SPARC was significantly increased in 10 tumour types (BRCA, CHOL, COAD, ESCA, GBM, HNSC, KIRC, KIRP, LIHC and READ) and significantly decreased only in PRAD (Fig. 1B). These results suggested that SPARC may mainly function as an oncogene in most cancer types. TCGA database also collected the RNASeq data of some recurrent and metastatic tumours. SPARC expression was significantly reduced in tissue from recurrent LGG and OV tumours compared with primary tumour tissues (Fig. 1C and D), but its clinical implication is unclear.

In TCGA dataset, the RNASeq data of PAAD contained only 4 normal specimens, and no significant change in SPARC expression was found. Thus, 17 pairs of RNA samples from PAAD and adjacent tissues were obtained and used to determine SPARC expression by RT-qPCR. The results confirmed that SPARC expression was significantly increased in PAAD tissues, compared with normal tissue (Fig. 1E).

SPARC is associated with the prognosis of various cancers. The expression level of SPARC was associated with the prognosis of various tumour types. Of the 33 cancer types in TCGA dataset, high expression of SPARC was associated with significantly worse prognosis in 9 cancer types, ACC, GBM, KIRP, LUSC, MESO, PAAD, SARC, STAD and UVM (Fig. 2A-I). However, SPARC may be a tumour suppressor gene in a few cancer types. Indeed, high SPARC expression was associated with improved prognosis in DLBL, KIRC, LGG and SKCM (Fig. 2J-M).

High expression of SPARC was associated with the worse prognosis of PAAD (Fig. 2F). Further analysis revealed that patients with high or low SPARC expression levels displayed similar survival times in the short term after diagnosis ( $<500$ days; Fig. 2F). Thus, it was hypothesized that the high early mortality rate caused by the high aggressiveness of PAAD meant that SPARC had little effect on early survival. However, when the follow-up time was extended, patients with different SPARC expression levels presented with completely different prognoses (Fig. 2F). This suggests that SPARC is associated with long-term prognosis of patients with PAAD.

SPARC is not associated with the pathological stage of $P A A D$. In general, SPARC expression increased with the PAAD pathological stage, but this was not statistically significant (Fig. 3A). The difference in SPARC expression between stage I and stage IIB or stage I and III-IV was not significant 
A

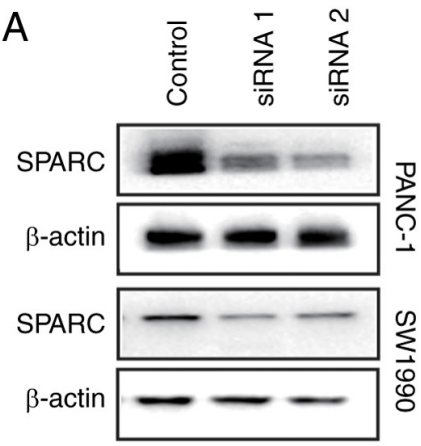

D

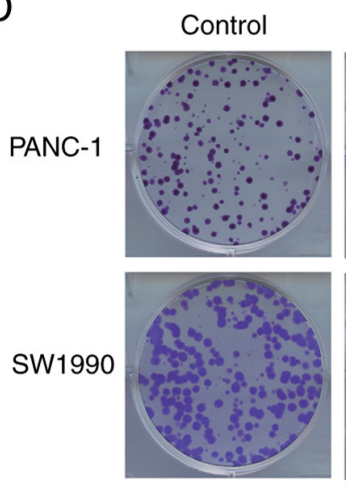

$\mathrm{F}$

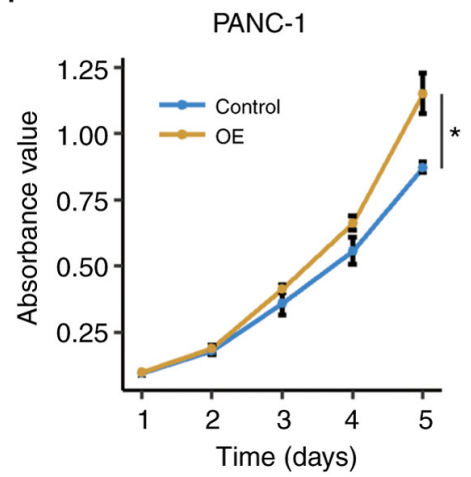

$\mathrm{B}$

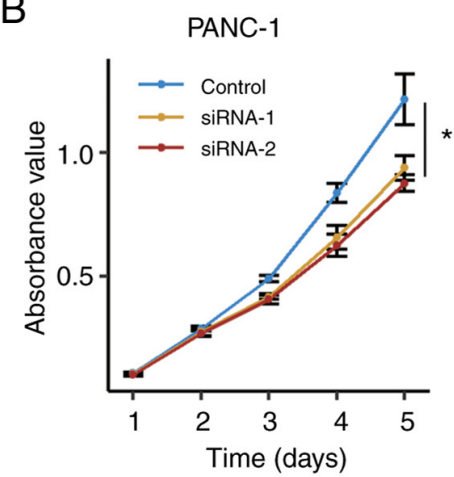

SiRNA1

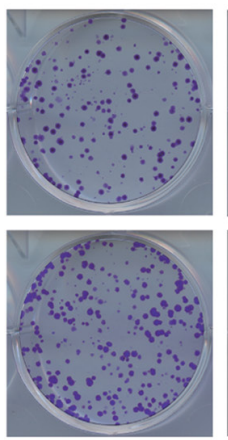

G

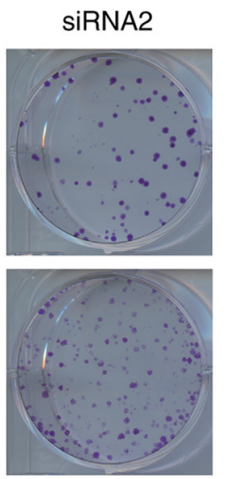

C

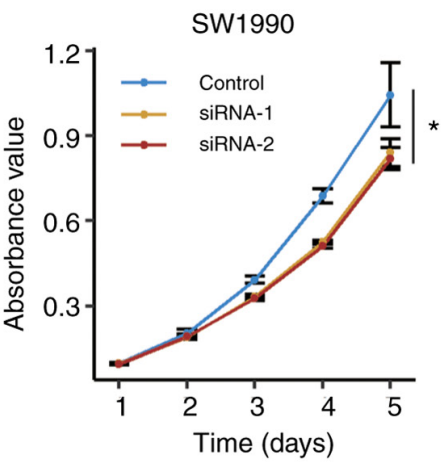

E

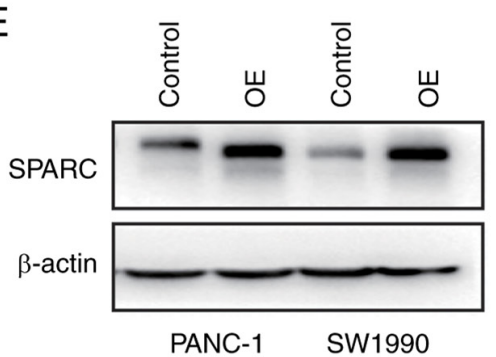

$\mathrm{H}$

SW1990

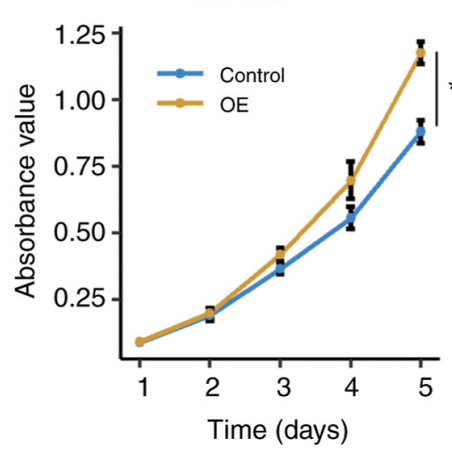

PANC-1

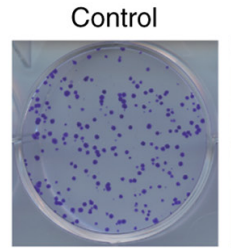

OE

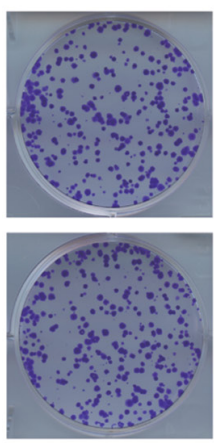

Figure 4. SPARC promotes the proliferation of PAAD cells. (A) Silencing of SPARC was achieved using two siRNA molecules. (B and C) CCK-8 assays showed that SPARC silencing impaired the proliferation of (B) PANC-1 cells and (C) SW1990 cells. n=3. "P $<0.05$, one-way ANOVA with Tukey's post-hoc test. (D) SPARC silencing impaired clone formation in PANC-1 and SW1990 cells. $n=3$. (E) SPARC OE in PANC-1 and SW1990 cells was verified by western blotting. (F and G) CCK-8 assays showed that SPARC OE increased the proliferation of (F) PANC-1 cells and (G) SW1990 cells. n=3. "P<0.05, unpaired two-tailed t-test. (H) SPARC OE increased clone formation PANC-1 and SW1990 cells. OE, overexpression; SPARC, secreted protein acidic and rich in cysteine; siRNA, small interfering RNA.

( $\mathrm{P}=0.16$ and 0.09 , respectively). The tumour size (T stage) and lymph node metastasis (N stage) were then analysed. SPARC protein expression also appeared to be associated with $\mathrm{T}$ stage, but this also did not reach significance (Fig. 3B). Patients with lymph node metastasis also showed an upward trend in SPARC expression, although this was not statistically significant $(\mathrm{P}=0.09$; Fig. 3C).

SPARC promotes the proliferation of PAAD cells. To identify whether SPARC affects the biological behaviour of PAAD cells in vitro, two siRNAs were designed to silence the expression of SPARC. Both siRNAs effectively silenced SPARC expression (Fig. 4A). SPARC silencing significantly impaired the proliferation of PANC-1 and SW1990 cells (Fig. 4B and C).
Moreover, SPARC silencing also impaired clone formation in PAAD cells (Fig. 4D), suggesting that SPARC was associated with proliferation in PAAD cells.

To further provide evidence that SPARC is implicated in PAAD cell proliferation, a rescue assay was carried out. A SPARC shRNA expression vector was constructed with the pLKO.1 vector and siRNA1 sequence. A SPARC OE vector was constructed and transfected into PANC-1 and SW1990 cells that were stably transfected with the SPARC shRNA vector. The ectopic expression of SPARC was confirmed with using a western blot assay (Fig. 4E). SPARC OE restored the proliferative ability of the PAAD cells $(\mathrm{P}<0.05$; Fig. 4F-H). Thus, these results indicated that SPARC was associated with the proliferation of PAAD cells. 
A
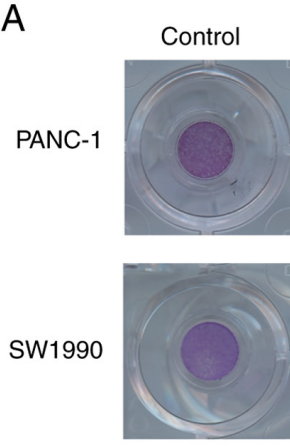

B

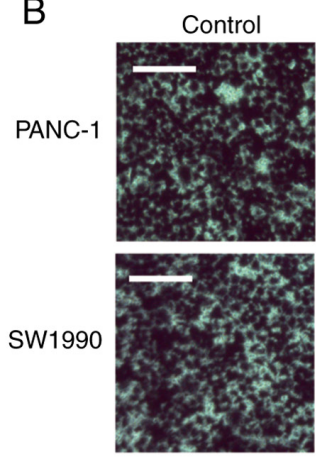

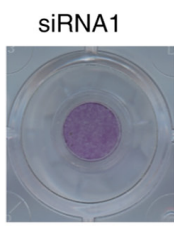

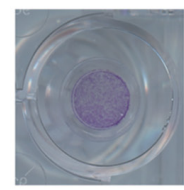
siRNA1

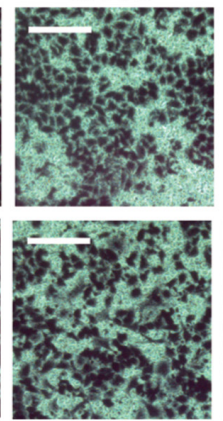

siRNA2
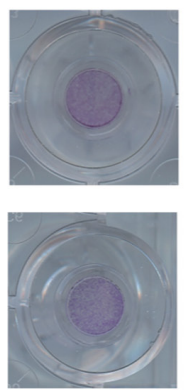

SiRNA2

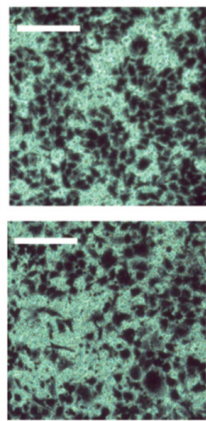

C
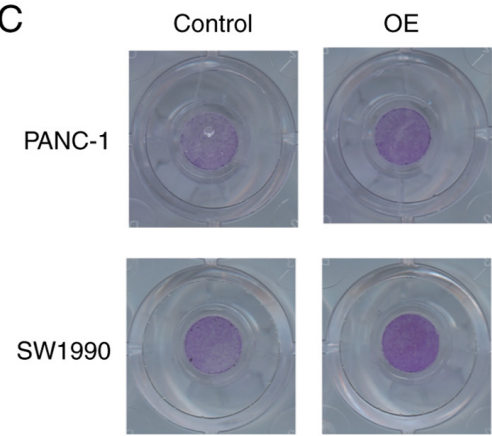

D

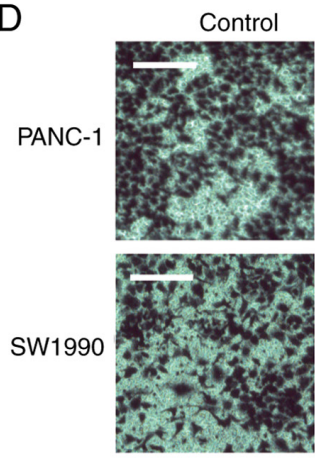

OE

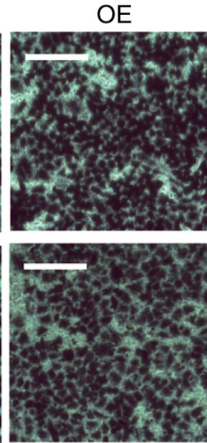

Figure 5. SPARC promotes the migration of PAAD cells. (A and B) Transwell assays showed that SPARC silencing impaired the migration of (A) PANC-1 and (B) SW1990 cells. (C and D) Transwell assays showed that SPARC OE increased the migration of (C) PANC-1 and (D) SW1990 cells. Scale bar, $100 \mu$ m. OE, overexpression; SPARC, secreted protein acidic and rich in cysteine; siRNA, small interfering RNA.

SPARC promotes the migration of PAAD cells. A Transwell assay was performed to determine whether SPARC could affect the migration of PAAD cells. The ability of the PAAD cells to cross the Transwell membrane was significantly impaired after SPARC was silenced (Fig. 5A and B). The changes in the migration ability of the PAAD cells following SPARC OE were also assessed. The migration of PAAD cells increased following SPARC OE (Fig. 5C and D).

SPARC regulates pancreatic cancer cell proliferation through autocrine secretion into the extracellular milieu. Considering that SPARC is an exocrine protein, western blot analysis was carried out in the culture supernatant of PAAD cells. Clear SPARC bands were detected in the supernatant of PAAD cells, immortalized normal acinar AR42J cells and 293T cells, confirming that SPARC was secreted into the extracellular milieu (Fig. 6A).

It was hypothesised that the SPARC protein could affect the proliferation and migration of PAAD cells when produced either by cancer cells or stromal cells and secreted to the stroma. This would explain why the prognosis of patients with PAAD is associated with SPARC expression levels of both tumour cells and stroma cells $(13,14)$. Therefore, the role of the SPARC protein in the extracellular milieu was examined. It was confirmed that the SPARC concentration in the supernatant of 293T cells was significantly decreased following siRNA silencing and increased by the SPARC OE vector, compared with scramble RNA or control vector, respectively (Fig. 6B). Before being treated with the supernatant from 293T cells treated with siRNA and OE vector, the PANC-1 and SW1990 cells were stably transfected with SPARC shRNA. The supernatant from the SPARC OE cells significantly promoted the proliferation of the PAAD cells, compared with the control group treated with a supernatant of SPARC-silenced 293T cells (Fig. 6C and D). PAAD cells treated with exogenous SPARC also showed increased clone formation (Fig. 6E). These results confirmed that SPARC from the extracellular milieu can promote the proliferation of PAAD cells.

Furthermore, it was hypothesised that this autocrineextracellularmilieu-cancer cell pathway may be necessary for SPARC function in cancer cells. As SPARC has a well-defined signal peptide, which is its N-terminal 17 amino acid residues, an expression vector that expresses the SPARC protein with deletion of signal peptide, referred to as pLenti-CMVSPARC ${ }^{\Delta s i g}$ peptide, was constructed (Fig. 6F). In both PANC-1 and SW1990 cells, endogenous SPARC was almost undetectable compared with the SPARC-Flag or SPARC $^{\Delta \text { sig peptide }}$-Flag fusion protein. Using an anti-Flag antibody, it was demonstrated that the SPARC-Flag fusion

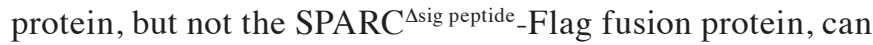
be effectively secreted to the extracellular milieu (Fig. 6G). The endogenous SPARC expression of the PANC-1 and SW1990 cells was silenced by stably transfecting with SPARC shRNA. Then, the control vector, SPARC OE vector and SPARC ${ }^{\Delta \text { sig peptide }}$ vector were transfected into the PAAD cells with the silencing of endogenous SPARC, and the proliferation of the PAAD cells was examined. Only the wildtype SPARC, but not SPARC ${ }^{\Delta \text { sig peptide }}$, effectively promoted the proliferation of PAAD cells (Fig. 6H and I). A clone-formation assay further confirmed this result (Fig. 6J). Thus, SPARC promotes the proliferation of PAAD cells through autocrine secretion into the extracellular milieu. 
A

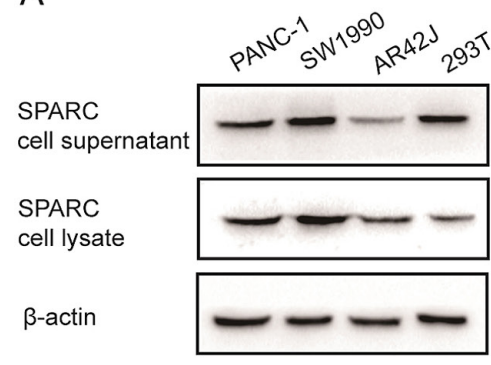

D

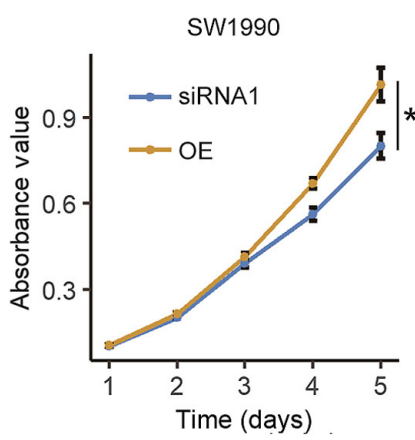

B

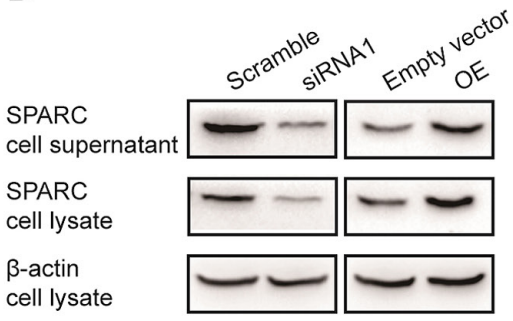

$\mathrm{E}$

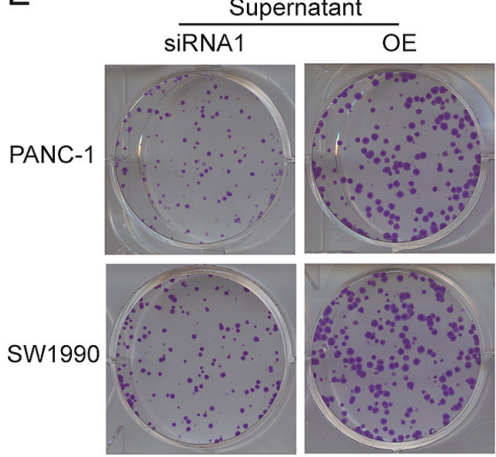

C

PANC-1

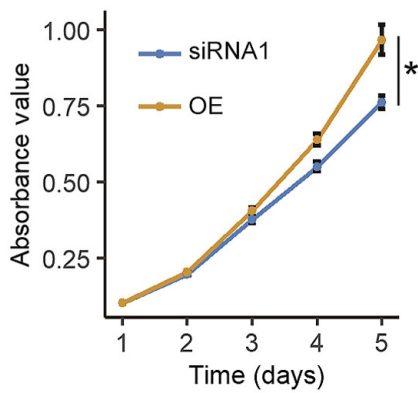

$\mathrm{F}$

Signal peptide Mature protein 3Flag

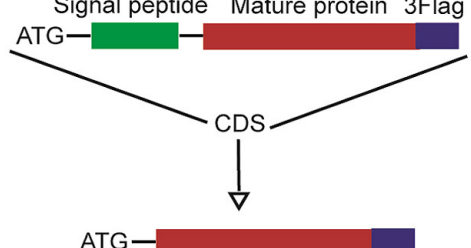

G

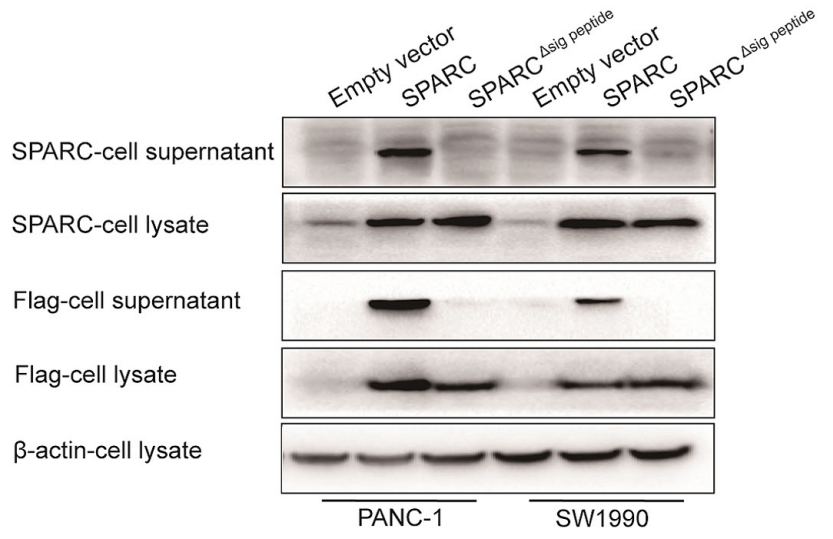

I

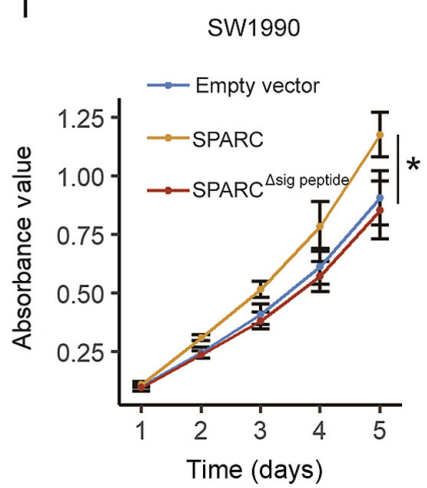

$\mathrm{H}$
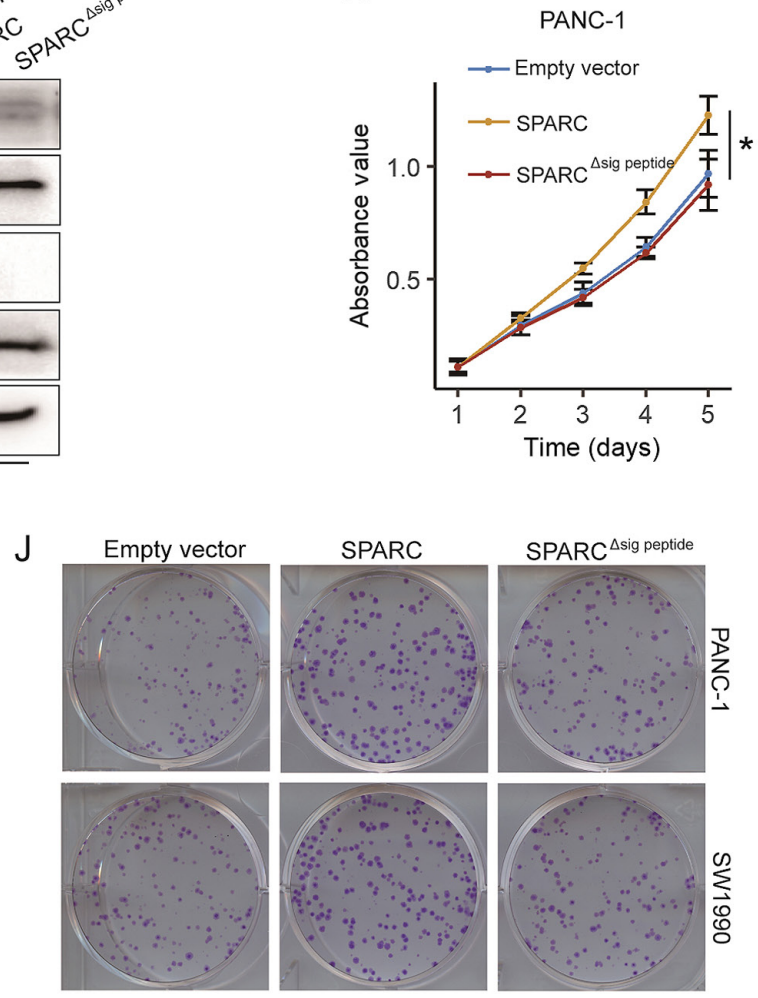

Figure 6. SPARC regulates pancreatic cancer cell proliferation through autocrine secretion into the extracellular milieu. (A) SPARC is detected in cell lysate and supernatant of PAAD cells, immortalized normal acinar AR42Jccells, and 293T cells. (B) Supernatant of 293T cells transfected with the SPARC siRNA has significant decreased concentration of SPARC protein, compared with cells transfected with scramble siRNA. The supernatant of 293T cells transfected with SPARC OE vector has increased concentration of SPARC protein, compared with the empty vector group. (C) Proliferation of PANC-1 cells transfected with SPARC OE supernatant increased significantly, compared with the cells treated with the SPARC-silenced supernatant $(\mathrm{n}=3)$. ${ }^{*} \mathrm{P}<0.05$, unpaired two-tailed t-test. (D) Proliferation of SW1990 cells treated with the SPARC OE supernatant increased significantly, compared with the cells treated with the SPARC-silenced supernatant $(\mathrm{n}=3)$. " $\mathrm{P}<0.05$, unpaired two-tailed $\mathrm{t}$-test. (E) Treatment with SPARC OE supernatant restores clone formation in PANC-1

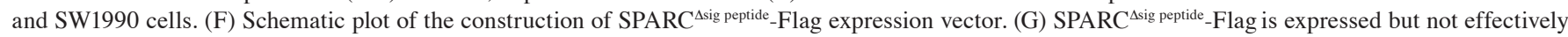
secreted to the extracellular milieu. (H and I) Wild-type SPARC, but not SPARC ${ }^{\Delta \text { sig peptide }}$, promotes the proliferation of (H) PANC-1 cells and (I) SW1990 cells $(\mathrm{n}=3) .{ }^{*} \mathrm{P}<0.05$, one-way ANOVA with Tukey's post-hoc test. (J) Colony formation in PAAD cells is restored by wild-type SPARC, but not SPARC ${ }^{\Delta s i g}$ peptide Quantitative data from three independent experiments was presented as mean \pm SD (error bars). OE, overexpression; SPARC, secreted protein acidic and rich in cysteine; siRNA, small interfering RNA. 

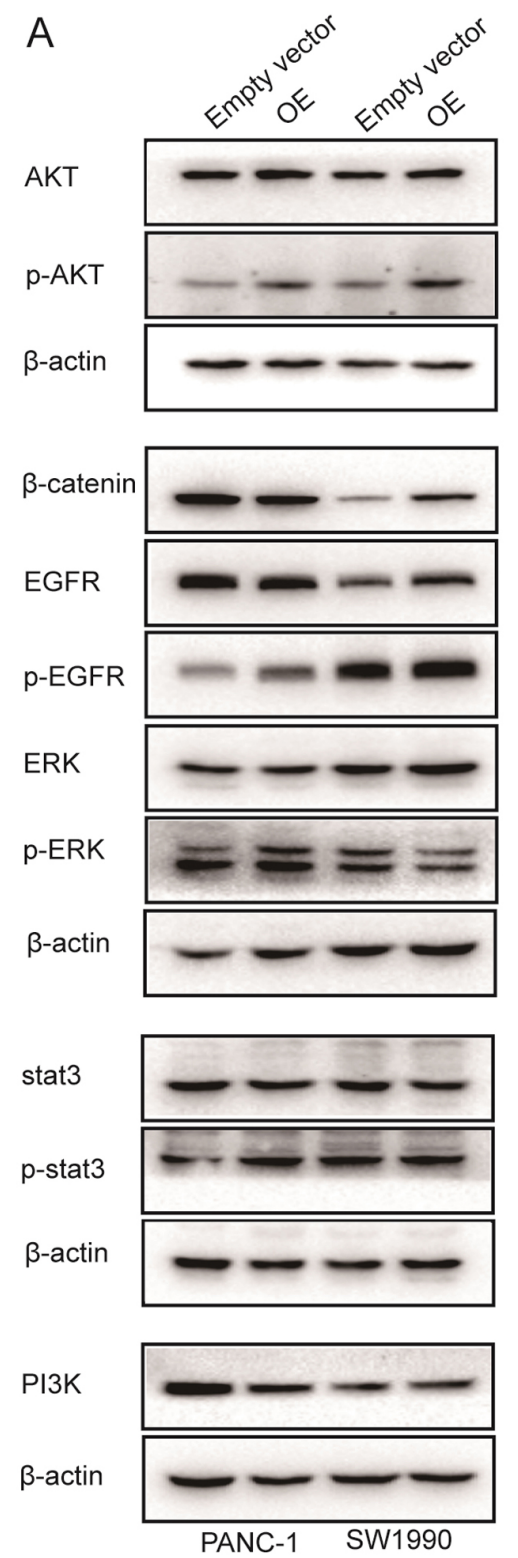
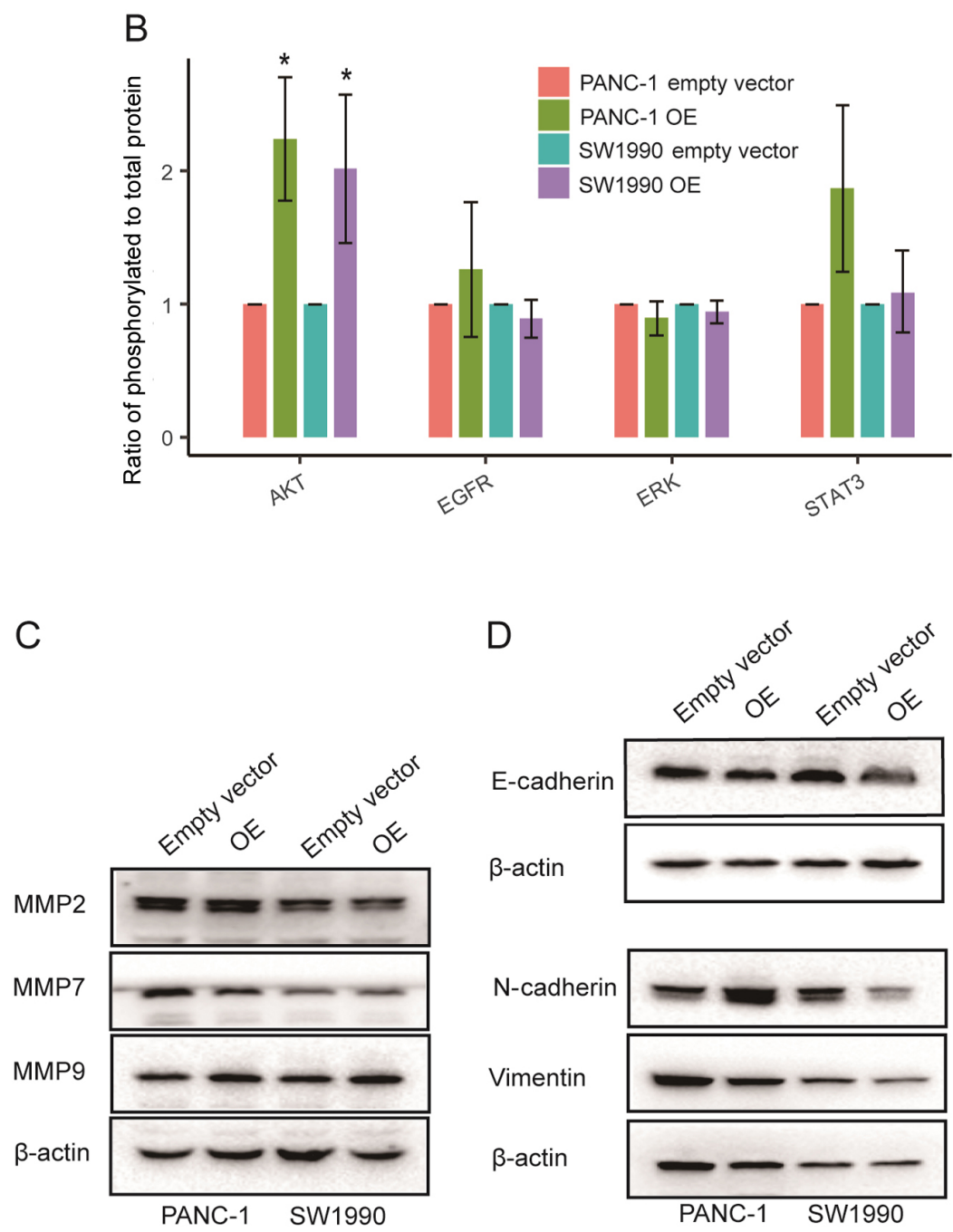

Figure 7. Mechanism of action of the SPARC protein. (A) SPARC significantly upregulates the phosphorylation AKT, but not STAT3, EGFR, ERK and $\beta$-catenin in PAAD cells. (B) Ratio of phosphorylated to total protein of AKT increased significantly in SPARC over-expressed PAAD cells. (C and D) SPARC had no significant and repeatable effect on the expression of the MMP2, MMP7, MMP9 and EMT related genes. "P<0.05, unpaired two-tailed t-test. OE, overexpression; SPARC, secreted protein acidic and rich in cysteine; MMP, matrix metalloproteinase.

Exploration of the mechanism of the SPARC protein. To elucidate how SPARC affects the proliferation and migration of PAAD cells, associated signalling pathways and molecules were examined. In PANC-1 and SW1990 cells, SPARC OE had no significant effect on the phosphorylation of STAT3, EGFR and ERK (Fig. 7A and B). Moreover, the expression of $\beta$-catenin, a critical molecule in the WNT pathway, had no significant and repeatable effect (Fig. 7A). However, the phosphorylation of AKT increased significantly following SPARC OE (Fig. 7A and B). As the abnormal activation of AKT plays an important role in the malignant proliferation of PAAD cells $(22,23)$, SPARC may regulate the proliferation of PAAD cells through the AKT pathway.

Furthermore, the effect of SPARC on matrix metalloproteinase (MMP) expression and epithelial-to-mesenchymal transition (EMT) in PAAD cells was also evaluated
(Fig. 7C and D). However, SPARC had no observable effect on the expression of MMP2, MMP7, MMP9, and EMT-related genes. Thus, the way in which SPARC regulates the migration of PAAD cells still needs further investigation.

\section{Discussion}

One of the major reasons that the SPARC gene has attracted the attention of scholars is that it plays multifaceted or even controversial roles in cancer formation and progression. In terms of cancer treatment, whether SPARC is a friend or a foe is still unclear. SPARC is associated with poor prognosis in breast cancer when expressed by cancer cells but improved prognosis when expressed by tumour stromal cells $(10,24)$. Moreover, in non-small cell lung cancer, SPARC from either cancer cells or stromal cells is associated with poor prognosis $(25,26)$. In 
addition, SPARC predicts improved prognosis in DLBL but poor prognosis in melanoma $(8,27)$. To construct a comprehensive picture of SPARC's function in cancer, a pan-cancer analysis of SPARC was carried out using a public dataset from TCGA covering 33 cancer types. By analysing the association between SPARC and the prognosis of different tumours, it was found that the function of SPARC seemed to mainly depend on the pathological cancer type rather than the organic or cellular origin. Moreover, SPARC predicted the distinct prognosis of LGG and GBM, which both stem from glial cells and occur in the brain or spine cord $(28,29)$, and KIRC and KIRP, which both stem from renal tubular epithelial cells (30). Meanwhile, SPARC seems associated with poor prognosis of adenocarcinoma (PAAD and STAD), whereas for COAD, LUAD and READ, the results did not reach significance. In addition, consistent with a previous report (8), SPARC was found to predict improved prognosis of lymphatic and hematopoietic cancer types, such as DLBL and LAML. Due to the influence of the mRNA turnover rate, ribosome-bound mRNA abundance and the protein turnover rate, mRNA abundance does not always accurately reflect protein content (31). Nevertheless, according to existing reports, the mRNA and protein expression of the SPARC gene in tumour tissues show a consistent trend $(32,33)$. To our knowledge, this study is the first to clarify the function of SPARC at the pan-cancer level, which could therefore help explain the inconsistencies seen in previous studies.

It was demonstrated that SPARC acts as an oncogene in PAAD. Moreover, SPARC is associated with poor prognosis of PAAD, and in the present in vitro research, we found that it promotes the proliferation and migration of PAAD cells. To a certain extent, the in vitro results of our work contradict some previous reports, in which SPARC was proposed to inhibit the proliferation and increase the chemosensitivity of PAAD cells (15-17). Thus, it may be proposed that cell type and experimental technique differences may be the direct cause of this inconsistency. However, the root cause may also be the versatility of SPARC. In PAAD, SPARC may have different functions in patients with different genomic alterations and molecular profiles. The possibility that SPARC may act as a tumor suppressor in some patients and some PAAD cell lines cannot be excluded, since subtypes of PAAD with significant molecular and clinical difference have been previously found (34).

Another question regarding SPARC and PAAD is whether the SPARC proteins that affect tumour prognosis come from tumour cells or tumour stromal cells. Our work confirmed that SPARC regulated PAAD proliferation only when secreted extracellularly. Since the SPARC that affects the proliferation of PAAD cells comes from the extracellular milieu, it may be inferred that the SPARC from both stroma cells and tumor cells can promote PAAD cell proliferation. In TCGA data used on this study, SPARC expression was determined via RNASeq; however, this method could not distinguish the cellular origin of SPARC. The optimal method to elucidate the source of SPARC may be immunohistochemistry (IHC), which requires paraffin-embedded clinical PAAD specimen or xenograft tissue. Unfortunately, there were not enough PAAD specimens to carry out IHC in the study. In addition, according to our past experience, the subcutaneous injection of PAAD cells in node mice does not result in massive fibroblasts or other types of stromal cell infiltration. The subcutaneous xenografts are mainly composed of cancer cells. Thus, an in vivo experiment may be useful in determining the effect of SPARC on in vivo growth of PAAD, but it cannot be used to distinguish the cellular origin of SPARC. The lack of IHC and in vivo experiments are a limitation of the present study, and the above questions should be explored in further studies.

The mechanisms underlying SPARC functions are complex. SPARC has been reported to facilitate the proliferation and metastasis of hepatocellular carcinoma via the ERK signalling pathway, promote cervical cancer cell proliferation by modulating the bax/bcl-2 ratio, and induce the migration of non-small cell lung cancer via WNK1/Snail signalling (35-37). In acute myeloid leukaemia, SPARC interacts with integrin-linked kinase (ILK) and promotes ILK signalling (38). Since AKT is an important downstream effector of ILK (39), it was hypothesised that SPARC may also promote AKT activation by interacting with ILK in PAAD cells.

In conclusion, the present study partly answered the aforementioned controversial roles of SPARC. Overall, SPARC exhibits regulatory potential and may play a role in PAAD progression, and its significance in cancer therapy merits further study.

\section{Acknowledgements}

The authors would like to thank Dr Yi Zhou (The First Affiliated Hospital of Wenzhou Medical University, Wenzhou, China) for her help in finishing supplementary western blot assay and for providing guidance for survival analysis.

\section{Funding}

The present study was supported by The Foundation of Wenzhou Science \& Technology Bureau (grant no. 2020Y0255).

\section{Availability of data and materials}

The datasets used and/or analyzed during the current study are available from the corresponding author on reasonable request. The datasets generated and/or analyzed during the current study are available in TCGA repository (https://portal. gdc.cancer.gov/).

\section{Authors' contributions}

$\mathrm{KP}, \mathrm{XH}$ and XJ performed the biological experiments, data analysis, statistical work and manuscript preparation. KP and XJ collected TCGA data and performed pan-cancer analysis of SPARC. XJ supervised the experimental work and finished manuscript proofreading. XJ designed the study and guarantees its integrity. KP, XH and XJ confirm the authenticity of all the raw data. All authors have read and approved the final manuscript.

\section{Ethics approval and consent to participate}

The present study was reviewed and approved by The Board of Wenzhou Medical University. Verbal informed consent was obtained from the patients. 


\section{Patient consent for publication}

Not applicable.

\section{Competing interests}

The authors declare that they have competing interests.

\section{References}

1. Termine JD, Kleinman HK, Whitson SW, Conn KM, McGarvey ML and Martin GR: Osteonectin, a bone-specific protein linking mineral to collagen. Cell 26: 99-105, 1981.

2. Mayer U, Aumailley M, Mann K, Timpl R and Engel J: Calcium-dependent binding of basement membrane protein BM-40 (osteonectin, SPARC) to basement membrane collagen type IV. Eur J Biochem 198: 141-150, 1991.

3. Gaudet P, Livstone MS, Lewis SE and Thomas PD: Phylogenetic-based propagation of functional annotations within the Gene Ontology consortium. Brief Bioinform 12: 449-462, 2011.

4. Nagaraju GP, Dontula R, El-Rayes BF and Lakka SS: Molecular mechanisms underlying the divergent roles of SPARC in human carcinogenesis. Carcinogenesis 35: 967-973, 2014.

5. Said N: Roles of SPARC in urothelial carcinogenesis, progression and metastasis. Oncotarget 7: 67574-67585, 2016.

6. Said N, Frierson HF, Sanchez-Carbayo M, Brekken RA and Theodorescu D: Loss of SPARC in bladder cancer enhances carcinogenesis and progression. J Clin Invest 123: 751-766, 2013

7. Chin D, Boyle GM, Williams RM, Ferguson K, Pandeya N, Pedley J, Campbell CM, Theile DR, Parsons PG and Coman WB: Novel markers for poor prognosis in head and neck cancer. Int J Cancer 113: 789-797, 2005.

8. Meyer PN, Fu K, Greiner T, Smith L, Delabie J, Gascoyne R, Ott G, Rosenwald A, Braziel R, Campo E, et al: The stromal cell marker SPARC predicts for survival in patients with diffuse large B-cell lymphoma treated with rituximab. Am J Clin Pathol 135: 54-61, 2011.

9. Yamanaka M, Kanda K, Li NC, Fukumori T, Oka N, Kanayama HO and Kagawa S: Analysis of the gene expression of SPARC and its prognostic value for bladder cancer. J Urol 166: 2495-2499, 2001.

10. Jones C, Mackay A, Grigoriadis A, Cossu A, Reis-Filho JS, Fulford L, Dexter T, Davies S, Bulmer K, Ford E, et al: Expression profiling of purified normal human luminal and myoepithelial breast cells: Identification of novel prognostic markers for breast cancer. Cancer Res 64: 3037-3045, 2004.

11. Liang JF, Wang HK, Xiao H, Li N, Cheng CX, Zhao YZ, Ma YB, Gao JZ, Bai RB and Zheng HX: Relationship and prognostic significance of SPARC and VEGF protein expression in colon cancer. J Exp Clin Cancer Res 29: 71, 2010.

12. Hariharan D, Saied A and Kocher HM: Analysis of mortality rates for pancreatic cancer across the world. HPB (Oxford) 10: $58-62,2008$

13. Infante JR, Matsubayashi H, Sato N, Tonascia J, Klein AP, Riall TA, Yeo C, Iacobuzio-Donahue $\mathrm{C}$ and Goggins $\mathrm{M}$ : Peritumoral fibroblast SPARC expression and patient outcome with resectable pancreatic adenocarcinoma. J Clin Oncol 25 319-325, 2007

14. Yu XZ, Guo ZY, Di Y, Yang F, Ouyang Q, Fu DL and Jin C: The relationship between SPARC expression in primary tumor and metastatic lymph node of resected pancreatic cancer patients and patients' survival. Hepatobiliary Pancreat Dis Int 16: 104-109, 2017

15. Fan X, Mao Z, Ma X, Cui L, Qu J, Lv L, Dang S, Wang X and Zhang J: Secreted protein acidic and rich in cysteine enhances the chemosensitivity of pancreatic cancer cells to gemcitabine. Tumour Biol 37: 2267-2273, 2016.

16. Xiao Y, Zhang H, Ma Q, Huang R, Lu J, Liang X, Liu X, Zhang Z, Yu L, Pang J, et al: YAP1-mediated pancreatic stellate cell activation inhibits pancreatic cancer cell proliferation. Cancer Lett 462: 51-60, 2019.

17. Mao Z, Ma X, Fan X, Cui L, Zhu T, Qu J, Zhang J and Wang X Secreted protein acidic and rich in cysteine inhibits the growth of human pancreatic cancer cells with G1 arrest induction. Tumour Biol 35: 10185-10193, 2014

18. Ellrott K, Bailey MH, Saksena G, Covington KR, Kandoth C, Stewart C, Hess J, Ma S, Chiotti KE, McLellan M, et al: Scalable open science approach for mutation calling of tumor exomes using multiple genomic pipelines. Cell Syst 6: 271-281.e7, 2018.
19. Almagro Armenteros JJ, Tsirigos KD, Sønderby CK, Petersen TN, Winther O, Brunak S, von Heijne G and Nielsen H: SignalP 5.0 improves signal peptide predictions using deep neural networks. Nat Biotechnol 37: 420-423, 2019.

20. Livak KJ and Schmittgen TD: Analysis of relative gene expression data using real-time quantitative PCR and the 2(-Delta Delta C(T)) method. Methods 25: 402-408, 2001.

21. Martincorena I, Raine KM, Gerstung M, Dawson KJ, Haase K, Van Loo P, Davies H, Stratton MR and Campbell PJ: Universal patterns of selection in cancer and somatic tissues. Cell 171: 1029-1041.e21, 2017.

22. Chio IIC, Jafarnejad SM, Ponz-Sarvise M, Park Y, Rivera K, Palm W, Wilson J, Sangar V, Hao Y, Öhlund D, et al: NRF2 promotes tumor maintenance by modulating mRNA translation in pancreatic cancer. Cell 166: 963-976, 2016.

23. Zhang H, Pan YZ, Cheung M, Cao M, Yu C, Chen L, Zhan L, He ZW, Sun CY: LAMB3 mediates apoptotic, proliferative, invasive, and metastatic behaviors in pancreatic cancer by regulating the PI3K/Akt signaling pathway. Cell Death Dis 10: 230, 2019.

24. Bergamaschi A, Tagliabue E, Sørlie T, Naume B, Triulzi T, Orlandi R, Russnes HG, Nesland JM, Tammi R, Auvinen P, et al: Extracellular matrix signature identifies breast cancer subgroups with different clinical outcome. J Pathol 214: 357-367, 2008.

25. Huang Y, Zhang J, Zhao YY, Jiang W, Xue C, Xu F, Zhao HY, Zhang Y, Zhao LP, Hu ZH, et al: SPARC expression and prognostic value in non-small cell lung cancer. Chin J Cancer 31: 541-548, 2012.

26. Koukourakis MI, Giatromanolaki A, Brekken RA, Sivridis E, Gatter KC, Harris AL and Sage EH: Enhanced expression of SPARC/osteonectin in the tumor-associated stroma of non-small cell lung cancer is correlated with markers of hypoxia/acidity and with poor prognosis of patients. Cancer Res 63: 5376-5380, 2003.

27. Massi D, Franchi A, Borgognoni L, Reali UM and Santucci M: Osteonectin expression correlates with clinical outcome in thin cutaneous malignant melanomas. Hum Pathol 30: 339-344, 1999.

28. Cancer Genome Atlas Research Network: Comprehensive genomic characterization defines human glioblastoma genes and core pathways. Nature 455: 1061-1068, 2008.

29. Perry A and Wesseling P: Histologic classification of gliomas. Handb Clin Neurol 134: 71-95, 2016.

30. Ricketts CJ, De Cubas AA, Fan H, Smith CC, Lang M, Reznik E, Bowlby R, Gibb EA, Akbani R, Beroukhim R, et al: The cancer genome atlas comprehensive molecular characterization of renal cell carcinoma. Cell Rep 23: 313-326.e5, 2018.

31. Maier T, Güell $M$ and Serrano L: Correlation of mRNA and protein in complex biological samples. FEBS Lett 583: 3966-3973, 2009

32. Zhang S, Jin J, Tian X and Wu L: hsa-miR-29c-3p regulates biological function of colorectal cancer by targeting SPARC. Oncotarget 8: 104508-104524, 2017.

33. Qu X, Gao D, Ren Q, Jiang X, Bai J and Sheng L: miR-211 inhibits proliferation, invasion and migration of cervical cancer via targeting SPARC. Oncol Lett 16: 853-860, 2018.

34. Cancer Genome Atlas Research Network. Electronic address: andrew_aguirre@dfci.harvard.edu; Cancer Genome Atlas Research Network: Integrated genomic characterization of pancreatic ductal adenocarcinoma. Cancer Cell 32: 185-203.e13, 2017.

35. Liu Y, Feng Y, Wang X, Yang X, Hu Y, Li Y, Zhang Q, Huang Y, Shi K, Ran C, et al: SPARC negatively correlates with prognosis after transarterial chemoembolization and facilitates proliferation and metastasis of hepatocellular carcinoma via ERK/MMP signaling pathways. Front Oncol 10: 813, 2020.

36. Chen J, Shi D, Liu X, Fang S, Zhang J and Zhao Y: Targeting SPARC by lentivirus-mediated RNA interference inhibits cervical cancer cell growth and metastasis. BMC Cancer 12: 464, 2012.

37. Hung JY, Yen MC, Jian SF, Wu CY, Chang WA, Liu KT, Hsu YL, Chong IW and Kuo PL: Secreted protein acidic and rich in cysteine (SPARC) induces cell migration and epithelial mesenchymal transition through WNK1/snail in non-small cell lung cancer. Oncotarget 8: 63691-63702, 2017.

38. Alachkar H, Santhanam R, Maharry K, Metzeler KH, Huang X, Kohlschmidt J, Mendler JH, Benito JM, Hickey C, Neviani P, et al: SPARC promotes leukemic cell growth and predicts acute myeloid leukemia outcome. J Clin Invest 124: 1512-1524, 2014.

39. Lynch DK, Ellis CA, Edwards PA and Hiles ID: Integrin-linked kinase regulates phosphorylation of serine 473 of protein kinase $B$ by an indirect mechanism. Oncogene 18: 8024-8032, 1999.

This work is licensed under a Creative Commons Attribution-NonCommercial-NoDerivatives 4.0 International (CC BY-NC-ND 4.0) License. 